\title{
Editorial
}

\section{Sustainable Agriculture and Soil Conservation}

\author{
Mirko Castellini $^{1, *} \mathbb{0}$, Mariangela Diacono ${ }^{1}{ }^{\mathbb{D}}$, Concetta Eliana Gattullo ${ }^{2}$ and Anna Maria Stellacci ${ }^{2}$ \\ 1 Council for Agricultural Research and Economics-Research Center for Agriculture and \\ Environment (CREA-AA), Via Celso Ulpiani 5, 70125 Bari, Italy; mariangela.diacono@crea.gov.it \\ 2 Department of Soil, Plant and Food Sciences, University of Bari "A. Moro", 70125 Bari, Italy; \\ concettaeliana.gattullo@uniba.it (C.E.G.); annamaria.stellacci@uniba.it (A.M.S.) \\ * Correspondence: mirko.castellini@crea.gov.it
}

\section{check for} updates

Citation: Castellini, M.; Diacono, M.; Gattullo, C.E.; Stellacci, A.M.

Sustainable Agriculture and Soil Conservation. Appl. Sci. 2021, 11, 4146. https://doi.org/10.3390/ app11094146

Received: 25 April 2021

Accepted: 27 April 2021

Published: 1 May 2021

Publisher's Note: MDPI stays neutral with regard to jurisdictional claims in published maps and institutional affiliations.

Copyright: (C) 2021 by the authors Licensee MDPI, Basel, Switzerland. This article is an open access article distributed under the terms and conditions of the Creative Commons Attribution (CC BY) license (https:// creativecommons.org/licenses/by/ $4.0 /)$.

\begin{abstract}
Soil degradation is one of the most topical environmental threats. A number of processes causing soil degradation, specifically erosion, compaction, salinization, pollution, and loss of both organic matter and soil biodiversity, are also strictly connected to agricultural activity and its intensification. The development and adoption of sustainable agronomic practices able to preserve and enhance the physical, chemical, and biological properties of soils and improve agroecosystem functions is a challenge for both scientists and farmers. This Special Issue collects 12 original contributions addressing the state of the art of sustainable agriculture and soil conservation. The papers cover a wide range of topics, including organic agriculture, soil amendment and soil organic carbon (SOC) management, the impact of SOC on soil water repellency, the effects of soil tillage on the quantity of SOC associated with several fractions of soil particles and depth, and SOC prediction, using visible and near-infrared spectra and multivariate modeling. Moreover, the effects of some soil contaminants (e.g., crude oil, tungsten, copper, and polycyclic aromatic hydrocarbons) are discussed or reviewed in light of the recent literature. The collection of the manuscripts presented in this Special Issue provides a relevant knowledge contribution for improving our understanding on sustainable agriculture and soil conservation, thus stimulating new views on this main topic.
\end{abstract}

Keywords: organic agriculture; soil amendment; soil organic carbon; soil management; soil water repellency; soil contamination; soil remediation; sustainable fruit growing; water conservation practices; multivariate statistical models for SOC prediction

\section{Introduction}

The ongoing global climate changes and the ever-increasing world population impose the adoption of agroecological or eco-sustainable production techniques to increase the resilience of the most fragile agrosystems [1]. For this reason, from many directions, a multidisciplinary scientific paradigm is increasingly suggested to better approach the complex problems concerning soil protection and sustainable agriculture [1-3].

The development and adoption of sustainable agronomic practices able to preserve and enhance the physical, chemical and biological properties of soils and improve agroecosystem functions is a challenge for both scientists and farmers [4]. In recent decades, much has been done because, on one hand, scientists have improved and simplified the measurement methods in specific research sectors, and on the other hand, the process of transferring research outputs to farmers has been enhanced. The latter has been considerably extended thanks to research funding granted by the National and Supranational Political Institution, which increasingly involves farmers and stakeholders. From a scientific point of view, much progress has been achieved in the development of sustainable practices based on minimal soil disturbance, the use of cover crops, organic mulching, crop rotations, water and nutrient conservation, recycling crop residues and livestock manure for soil amendment, precision agriculture and so on, and many reviews have summarized the state of the art and traced the future trajectories (among others, refs. [5-9]). However, 
much remains to be explored, and Special Issues stimulating the scientific community on these main topics are desirable.

The main goal of this Special Issue (SI) is to collect and present recent research on sustainable agriculture and soil conservation. A synthesis of the main results is reported in the following section.

\section{Overview of This Special Issue}

This SI collects 12 original contributions focused on soil use and management, soil conservation, as well as on the impact of some pollutants on the soil. Specifically, the SI collects nine research papers [10-18], two reviews [19,20] and one methodological work [21]. Eight of the twelve manuscripts considered the effects of soil use and management (topic I) [10-16,21], while the remaining four [17-20] evaluated the impact of some soil contaminants (e.g., crude oil, tungsten, copper and polycyclic aromatic hydrocarbons) (topic II). This grouping was used to detail the contents and for the reader's usefulness.

Regarding the aforementioned nine investigations (i.e., research papers), seven were carried out in the field [10-16], while the others accounted for pot [17] or microcosm [18] experiments. From a geographical point of view, five "field open-air" investigations were carried out in Italy (three in the south [12,13,16], one in the center [15] and one in the north [10] of Italy), while the remaining investigations were in Brazil [14] and China [11].

Topic I comprises eight papers. Pastorelli et al. [10] investigated the short-term effects of digestate on soil properties through a holistic approach, thus investigating the soil's physical, chemical and microbiological properties and their interactions. The digestate effects were evaluated in the two maize growing seasons within a 2-year maize-triticale rotation to feed the biogas plant. The main results showed that the digestate (1) increased the soil's total organic $\mathrm{C}$, total $\mathrm{N}$ and $\mathrm{K}$ contents, (2) did not affect the soil bulk density while transiently improving the soil aggregate stability, (3) decreased the soil transmission pores (50-500 $\mu \mathrm{m}$ size) proportion as well as increasing the fissures ( $>500 \mu \mathrm{m}),(4)$ only transiently affected the soil's microbial community and did not cause soil contamination from Clostridiaceae-related bacteria, (5) significantly impaired seed germination when applied at low dilution ratios and (6) did not improve the crop yield, as it was similar to usual mineral fertilization. In the context of energy crop farming, the authors concluded that the agronomic recycling and usage of digestate from biogas production assured a sustainable crop yield and soil quality. Therefore, digestate was confirmed as a valid resource for sustainable management of the soil's fertility.

Wang et al. [11] investigated the prediction of soil organic matter (SOM) from visible and near-infrared (VNIR) spectra, taking into account the presence of nonlinear relationships and spatial heterogeneity conditions. Specifically, they combined the proposed partial least squares-based multivariate adaptive regression spline (PLS-MARS) method and a regional multivariable associate rule mining and Rank-Kennard-Stone method (MVARC$\mathrm{R}-\mathrm{K}-\mathrm{S}$ ) to construct a nonlinear prediction model to realize local optimality considering spatial heterogeneity. The method, which was applied and validated for a case study in Hubei (China), was able to filter the spatial autocorrelation present in the investigated area. In addition, it showed improvements compared with some available methods in terms of accuracy and robustness, suggesting the reliability of the proposed prediction model.

Losciale et al. [12] compared four soil management strategies at a peach orchard, namely (1) completely tilled (control); (2) mulched with reusable reflective plastic film; (3) mulching with a leguminous cover crop flattened after the peach fruit set; (4) completely tilled and irrigated with the water volumes of the treatment with reflective mulching. The effects on the soil features, water use efficiency (WUE), tree functionality, fruit growth and quality, yield and water productivity were investigated. The main results showed that when using $50 \%$ of the regular irrigation, reusable reflective mulching reduced the water loss and soil carbon mineralization while not affecting (and sometimes increasing) the net carbon assimilation, yield and fruit size. Consequently, water productivity was drastically increased. The investigation allowed for the conclusion that a reflective mulching strategy 
is promising from the point of view of WUE optimization, especially in hot and dry areas with clay soils and low organic matter contents.

De Mastro et al. [13] investigated the effects of different soil management methods (conventional tillage, CT, minimum tillage, MT, and no-tillage, NT), both with fertilization and without fertilization, on the quantity of SOC at different soil depths and soil particle size fractions. Diffuse reflectance infrared Fourier transform spectroscopy (DRIFT) was also performed to obtain information on both the SOC quality and the mineralogical composition of these soil fractions. The results showed that $\mathrm{CT}$ provided the highest amount of the finest fraction, while fertilization improved the microbial community with the increase of soil microaggregates. The coarse fraction was highest in the upper soil layer, while the finest fraction was highest in the deepest one. The greatest OC content was observed in the topsoil layer and in the finest soil fraction. The DRIFT analysis could provide information about the quality of the main minerals present in the different soil size fractions.

Lozano-Baez et al. [14] measured both the unsaturated and saturated soil hydraulic conductivity, determined with simple and low-cost field infiltration methods-a minidisk tension infiltrometer, MDTI [22], and Beerkan [23]—for three land covers, namely (1) pastures, (2) 9-year-old restored forest and (3) remnant forest. The paper, which was relevant because it provided the first measurements of soil water repellency (SWR) in the Brazilian Atlantic Forest, proved that MDTI and Beerkan infiltrations gave complementary information, highlighting increasing hydraulic conductivities, especially at the remnant forest plots, when moving from near-saturated to saturated conditions. Moreover, measuring the hydraulic conductivity with MDTI allowed the estimation of the macroscopic capillary length [24], which is a hydrodynamic soil parameter useful for investigating the impact of soil management on water saving [25]. The authors concluded that the applied approach (MDTI + Beerkan) allowed the design of better estimates of the saturated soil hydraulic conductivity under challenging field conditions, such as soil water repellency (SWR).

Amoriello et al. [15] evaluated the impact of soil amendment with biochar from brewers' spent grain (BSG) on hop growth. The field investigation was carried out in Rieti (central Italy). Three different German cultivars of hop plant were considered, and biochar was added at a $20 \%$ level. Biochar's effects on root development, shoots, bine length and crop yield were evaluated using multivariate image analysis and general linear models. The results showed that biochar significantly improved root growth. Overall, no variability in shoots, number of leaves or bine length was observed between the two treatments for all cultivars or among the genotypes considered. Moreover, soil amendment significantly improved the yield (number of cones). The authors concluded that BSG-derived biochar could be useful for improving hop plant growth and cone production because it can supply key nutrients for plant growth and improve the soil's properties.

Montemurro et al. [16] evaluated the production capacity of organic horticultural systems and the ex-post sustainability using a new multi-attribute decision model named DEXi-met. Specifically, they compared three horticultural systems in Metaponto (south Italy): (1) ECO (organic system with full implementation of agroecological strategies, agroecological services crops (ASC), strip cultivation and organic amendment), (2) GM (organic system with the introduction of ASC) and (3) no ASC (organic system without agroecological services crops). The qualitative response of the DEXi-met model suggested that the treatments with ASC returned similar total energy outputs, indicating the positive effect of this agroecological practice. Therefore, the authors pointed out that the ECO system could contribute to building up more complex agroecosystems, increasing both the resilience and biodiversity in organic agriculture.

Sofo and Ricciuti [21] presented a standardized method, named Biolog ${ }^{\circledR}$ EcoPlates $^{\mathrm{TM}}$ (Biolog Inc., Hayward, CA, USA), to analyze the functional diversity of bacterial communities by means of measuring their ability to oxidize carbon substrates. Specifically, they reported a detailed methodological procedure which was easy to follow and reproduce (i.e., a detailed and step-by-step description of soil preparation, dispersion and dilution, 
optimal bacterial density of the inoculum and so on), based on previous data and experiments. To this aim, a case study of the soils of a Mediterranean olive orchard was reported for comparing the methods and justifying the methodological protocol proposed. The authors emphasized that the results of this methodological paper could be important for correctly evaluating and comparing the microbiological fertility of the soils managed with sustainable, conservation-based practices or conventional, non-conservation-based ones.

Topic II comprises four papers. Zhang et al. [17] evaluated the impact of differentlevels of crude oil on the soil properties, physiological and chemical parameters of maize leaves and the phenanthrene content in the leaf. The results showed that (1) the soil water content significantly increased as the total petroleum hydrocarbons increased, and the soil electrical conductivity significantly increased compared with the control, and (2) the stomatal length and density, leaf $\mathrm{K}$ and Na contents and phenanthrene leaf concentration decreased in the contaminated soil compared with the reference group. The authors concluded that the stomata structure of maize could be influenced by crude oil, thus possibly controlling the accumulation of polycyclic aromatic hydrocarbons in aerial tissues. Practical implications for contaminated soil management were also hypothesized. Indeed, because stomata can play a key role in the aerial uptake of pollutants, regulation of stomatal movement can be usefully applied in phytoremediation of contaminated soil.

Petruzzelli and Pedron [18] investigated the influence of the soil characteristics on the tungsten uptake by maize for three different soils—-Histosol, Vertisol and Fluvisol—in the Mediterranean area. Tungsten is largely used in high-tech and military industries. Therefore, soils are increasingly enriched in this element, and the possible transfer in the food chain represents a current issue in agroenvironmental studies. The results showed that tungsten concentrations in the roots and shoots increased with the increasing soil pH and decreased with the increasing organic matter. Further investigations were suggested by the authors to fully understand the mechanisms of tungsten transfer from the soil to the plant and the corresponding environmental impact of this element on human health.

Cesco et al. [19] reviewed the issue of copper $(\mathrm{Cu})$ accumulation in European vineyard soils due to massive application from different sources (among others, metal-contaminated sludges and $\mathrm{Cu}$-based pesticides for crop defense against pathogens). Although $\mathrm{Cu}$ is an essential micronutrient for equilibrated crop growth, excessive $\mathrm{Cu}$ concentrations in soil may lead to severe symptoms of toxicity, which are beginning to be recognized in crops and, particularly, in acidic soils. After dealing with the state of the art on this topic, they listed and discussed several current challenges, including (1) copper effects on soil agrobiodiversity, (2) rhizosphere management (management of soil-root-microorganism interactions), (3) biotechnologies and breeding for a more resistant plant material and (4) smart viticulture.

Sayara and Sánchez [20] reviewed the topic of bioremediation of contaminated soils due to the accumulation of polycyclic aromatic hydrocarbons (PAHs). Specifically, they focused on the application of compost as a type of biostimulation or bioaugmentation treatment to facilitate the bioremediation of soils contaminated with PAHs. Moreover, the authors reviewed the use of composting as an ex situ bioremediation strategy for PAH-contaminated soils. After dealing with the properties and sources of PAHs, they discussed the bioremediation of PAH-contaminated soils by composting and bioaugmentation (reviewing the effects of PAH characteristics and concentrations, temperatures of treatment, organic co-substrate stability and the mixing ratio), also describing the consequences of PAH bioavailability and biodegradation pathways. The authors concluded that, although the use of compost and composting in several remediation strategies significantly improved the removal of PAHs in contaminated soils, further investigations are needed in this research field.

\section{Conclusions}

The 12 manuscripts presented in this Special Issue can contribute to improving our understanding of sustainable agriculture and soil conservation through the development and 
adoption of specific agronomic practices able to preserve and enhance the physical, chemi$\mathrm{cal}$ and biological properties of soils. The derived improvement of agroecosystem functions goes in the direction desired by both scientists and farmers. The investigations presented considered various crops, three different countries and multiple pedoclimatic conditions.

For the reader's convenience, the collected contributions were summarized in two main groups to provide results on the effects of soil use and management (topic I) and on the impact of some soil contaminants (e.g., crude oil, tungsten, copper and polycyclic aromatic hydrocarbons) (topic II).

The common conclusions drawn by the authors of this SI agree on the importance of both improving the available options for soil conservation and developing, implementing and sharing new techniques for the sustainable use of the soil.

Funding: This research received no external funding.

Conflicts of Interest: The authors declare no conflict of interest.

\section{References}

1. Leippert, F.; Darmaun, M.; Bernoux, M.; Mpheshea, M. The Potential of Agroecology to Build Climate-Resilient Livelihoods and Food Systems; FAO and Biovision: Rome, Italy, 2020. [CrossRef]

2. Wezel, A.; Herren, B.G.; Kerr, R.B.; Barrios, E.; Gonçalves, A.L.R.; Sinclair, F. Agroecological principles and elements and their implications for transitioning to sustainable food systems. A review. Agron. Sustain. Dev. 2020, 40, 40. [CrossRef]

3. Gargano, G.; Licciardo, F.; Verrascina, M.; Zanetti, B. The Agroecological Approach as a Model for Multifunctional Agriculture and Farming towards the European Green Deal 2030-Some Evidence from the Italian Experience. Sustainability 2021, 13, 2215. [CrossRef]

4. Diacono, M.; Persiani, A.; Castellini, M.; Giglio, L.; Montemurro, F. Intercropping and rotation with leguminous plants in organic vegetables: Crop performance, soil properties and sustainability assessment. Biol. Agric. Hortic. 2021. [CrossRef]

5. Liu, W.; Shao, X.-F.; Wu, C.-H.; Qiao, P. A systematic literature review on applications of information and communication technologies and blockchain technologies for precision agriculture development. J. Clean. Prod. 2021, 298, 126763. [CrossRef]

6. Bahinipati, C.S.; Kumar, V.; Viswanathan, P.K. An evidence-based systematic review on farmers' adaptation strategies in India. Food Sec. 2021. [CrossRef]

7. Ke, H.; Zhang, J.; Zeng, Y. Knowledge domain and emerging trends of agricultural waste management in the field of social science: A scientometric review. Sci. Total Environ. 2019, 670, 236-244.

8. Mak, M.W.; Xiong, X.; Tsang, D.C.W.; Yu, I.K.M.; Poon, C.S. Sustainable food waste management towards circular bioeconomy: Policy review, limitations and opportunities. Bioresour. Technol. 2020, 297, 122497. [CrossRef]

9. Lozano-Baez, S.E.; Domínguez-Haydar, Y.; Meli, P.; van Meervel, I.; Vásquez, K.V.; Castellini, M. Key Gaps in Soil Monitoring during Forest Restoration in Colombia. Restor. Ecol. 2021. [CrossRef]

10. Pastorelli, R.; Valboa, G.; Lagomarsino, A.; Fabiani, A.; Simoncini, S.; Zaghi, M.; Vignozzi, N. Recycling Biogas Digestate from Energy Crops: Effects on Soil Properties and Crop Productivity. Appl. Sci. 2021, 11, 750. [CrossRef]

11. Wang, X.; Yang, C.; Zhou, M. Partial Least Squares Improved Multivariate Adaptive Regression Splines for Visible and NearInfrared-Based Soil Organic Matter Estimation Considering Spatial Heterogeneity. Appl. Sci. 2021, 11, 566. [CrossRef]

12. Losciale, P.; Gaeta, L.; Manfrini, L.; Tarricone, L.; Campi, P. Orchard Floor Management Affects Tree Functionality, Productivity and Water Consumption of a Late Ripening Peach Orchard under Semi-Arid Conditions. Appl. Sci. 2020, 10, 8135. [CrossRef]

13. De Mastro, F.; Cocozza, C.; Brunetti, G.; Traversa, A. Chemical and Spectroscopic Investigation of Different Soil Fractions as Affected by Soil Management. Appl. Sci. 2020, 10, 2571. [CrossRef]

14. Lozano-Baez, S.E.; Cooper, M.; de Barros Ferraz, S.F.; Ribeiro Rodrigues, R.; Lassabatere, L.; Castellini, M.; Di Prima, S. Assessing Water Infiltration and Soil Water Repellency in Brazilian Atlantic Forest Soils. Appl. Sci. 2020, 10, 1950. [CrossRef]

15. Amoriello, T.; Fiorentino, S.; Vecchiarelli, V.; Pagano, M. Evaluation of Spent Grain Biochar Impact on Hop (Humulus lupulus L.) Growth by Multivariate Image Analysis. Appl. Sci. 2020, 10, 533. [CrossRef]

16. Montemurro, F.; Persiani, A.; Diacono, M. Organic Vegetable Crops Managed with Agro-Ecological Practices: Environmental Sustainability Assessment by DEXi-met Decision Support System. Appl. Sci. 2019, 9, 4148. [CrossRef]

17. Zhang, C.; Huang, H.; Zhou, Y.; Lin, H.; Xie, T.; Liao, C. Stomatal Response of Maize (Zea mays L.) to Crude Oil Contamination in Soils. Appl. Sci. 2019, 9, 4074. [CrossRef]

18. Petruzzelli, G.; Pedron, F. Influence of Increasing Tungsten Concentrations and Soil Characteristics on Plant Uptake: Greenhouse Experiments with Zea mays. Appl. Sci. 2019, 9, 3998. [CrossRef]

19. Cesco, S.; Pii, Y.; Borruso, L.; Orzes, G.; Lugli, P.; Mazzetto, F.; Genova, G.; Signorini, M.; Brunetto, G.; Terzano, R.; et al. A Smart and Sustainable Future for Viticulture Is Rooted in Soil: How to Face Cu Toxicity. Appl. Sci. 2021, 11, 907. [CrossRef]

20. Sayara, T.; Sánchez, A. Bioremediation of PAH-Contaminated Soils: Process Enhancement through Composting/Compost. Appl. Sci. 2020, 10, 3684. [CrossRef] 
21. Sofo, A.; Ricciuti, P. A Standardized Method for Estimating the Functional Diversity of Soil Bacterial Community by Biolog ${ }^{\circledR}$ EcoPlates ${ }^{\mathrm{TM}}$ Assay-The Case Study of a Sustainable Olive Orchard. Appl. Sci. 2019, 9, 4035. [CrossRef]

22. Alagna, V.; Iovino, M.; Bagarello, V.; Mataix-Solera, J.; Lichner, L. Application of minidisk infiltrometer to estimate water repellency in Mediterranean pine forest soils. J. Hydrol. Hydromech. 2017, 65, 254-263. [CrossRef]

23. Castellini, M.; Di Prima, S.; Moret-Fernández, D.; Lassabatere, L. Rapid and accurate measurement methods for determining soil hydraulic properties: A review. J. Hydrol. Hydromech. 2021, 69, 1-19. [CrossRef]

24. Di Prima, S.; Stewart, R.D.; Castellini, M.; Bagarello, V.; Abou Najm, M.R.; Pirastru, M.; Giadrossich, F.; Iovino, M.; AnguloJaramillo, R.; Lassabatere, L. Estimating the macroscopic capillary length from Beerkan infiltration experiments and its impact on saturated soil hydraulic conductivity predictions. J. Hydrol. 2020, 125159. [CrossRef]

25. Castellini, M.; Stellacci, A.M.; Mastrangelo, M.; Caputo, F.; Manici, L.M. Estimating the soil hydraulic functions of some olive orchards: Soil management implications for water saving in soils of Salento peninsula (southern Italy). Agronomy 2020, 10, 177. [CrossRef] 